\title{
Responsabilidade social na educação superior: contribuições da psicologia escolar
}

\author{
Juliana Eugênia Caixeta \\ Maria do Amparo de Sousa
}

\begin{abstract}
Resumo
A Educação Superior é responsável pelo processo de formação integral do profissional, pela produção de novos conhecimentos e pelo desenvolvimento da sociedade. Instituições de Educação Superior (IES) responsáveis são aquelas que se ocupam e se preocupam com o desenvolvimento das pessoas com as quais interagem, com suas relações entre si e com o meio ambiente e, também, com o mercado de trabalho e com as comunidades globais. Dessa forma, ações de responsabilidade social das IES indicam o comprometimento das instituições com sua função ética, política e social. Ancorando-nos em uma perspectiva institucional e preventiva de atuação em psicologia escolar, desenvolvemos uma pesquisa-ação em uma faculdade privada brasileira com o objetivo de planejar, executar e avaliar ações como trotes, cursos de extensão e de formação docente e técnica, e apoio psicopedagógico. O resultado da pesquisa foi a construção de uma proposta multidimensional de responsabilidade social que contempla diferentes dimensões da IES.
\end{abstract}

Palavras-chave: Psicologia escolar, responsabilidade social, educação superior.

\section{Social responsibility in higher education: contributions from the school psychology}

\begin{abstract}
Higher education is responsible for the process of integral professional education, for the production of new knowledge and for the development of society. Higher Education Institutions (HEls) are those that take care of the development of people with whom they interact, their relationships with each other and with the environment, and also with the labor market and global communities. Thus, actions of social responsibility of the $\mathrm{HEI}$ indicate their commitment with their ethical, political and social roles. Anchoring in a preventive institutional perspective of performance in Educational Psychology, we developed an action research in a Brazilian private College aiming to plan, implement and evaluate actions such as hazing, extension courses and teacher and technicians training, educational psychology support, among others. The research result suggests the construction of a multidimensional proposal of social responsibility which takes in account various dimensions of the HEI.
\end{abstract}

Keywords: School psychology, social responsibility, higher education.

\section{Responsabilidad social en la educación superior:aportes de la psicología escolar}

\section{Resumen}

La Educación Superior es responsable por el proceso de formación integral del profesional, por la producción de nuevos conocimientos y por el desarrollo de la sociedad. Instituciones de Educación Superior (IES) responsables son las que se ocupan y se preocupan con el desarrollo de las personas con quienes interactúan, sus relaciones entre sí y con el medio ambiente, así como también con el mercado de trabajo y con las comunidades globales. Por lo tanto, acciones de responsabilidad social de las IES indican el compromiso de las instituciones con su función ética, política y social. Apoyándonos en perspectiva institucional y preventiva de actuación en psicología escolar desarrollamos una investigaciónacción en universidad privada brasileña con el objetivo de planificar, ejecutar y evaluar acciones como ritos de iniciación universitaria, cursos de extensión y de capacitación docente y técnica, y el apoyo psicopedagógico. El resultado de la investigación fue la construcción de una propuesta multidimensional de Responsabilidad Social que contempla diferentes dimensiones de la IES.

Palabras clave: Psicología escolar, responsabilidad social, educación superior. 


\section{Introdução}

A psicologia escolar é um campo de atuação, de pesquisa e de produção de conhecimento que tem como objetivo a mediação dos processos de aprendizagem e de desenvolvimento humano. Entende-se desenvolvimento humano, segundo a perspectiva da psicologia sociocultural, como processos de transformações que ocorrem na interação eu-outro, marcadas pelas negociações de significados que se concretizam nessas interações no contexto cultural.

Contemporaneamente, a psicologia escolar tem inovado sua ação para estudos e práticas orientados por uma perspectiva preventiva, relacional e institucional de atuação (Guzzo, 2001; Marinho-Araújo, 2009; Martínez, 2010; Oliveira \& Marinho-Araújo, 2009). Nessa direção, Martínez (2010) aponta como ações emergentes do psicólogo escolar: o diagnóstico, análise e intervenção institucional; construção, acompanhamento e avaliação da proposta pedagógica; participação no processo de seleção e formação dos membros da equipe pedagógica; coordenação de oficinas direcionadas ao desenvolvimento integral dos alunos; realização de pesquisas com o objetivo de aprimorar o processo educativo; envolvimento com a implementação das políticas públicas, entre outras.

No contexto da Educação Superior, as funções do psicólogo escolar incluem: assessoria ao processo de ensino-aprendizagem; participação nos processos de seleção e treinamento do corpo docente e técnico; docência em Psicologia e em outras áreas do conhecimento; realização de pesquisas; envolvimento com publicação científica em psicologia escolar; planejamento, desenvolvimento e avaliação de programas e cursos na área da Psicologia, entre outras (Witter, 1999).

Marinho-Araújo (2009) complementa, propondo três dimensões de intervenção institucional para a psicologia escolar, a saber: (a) Gestão de Políticas, Programas e Processos Educacionais, (b) Propostas Pedagógicas e funcionamento de cursos e (c) Perfil do estudante. Na primeira dimensão, o psicólogo escolar pode assessorar ações ligadas à gestão institucional e participar da elaboração e revisão do Plano de Desenvolvimento Institucional; participar da ambientação de novos docentes e funcionários; atuar em programas de formação continuada de docentes, coordenadores e funcionários; acompanhar a autoavaliação institucional. Em relação à dimensão das Propostas Pedagógicas, a autora sugere colaboração na análise das diretrizes curriculares que orientam o trabalho pedagógico; acompanhamento do processo de ensino e aprendizagem à luz das diretrizes curriculares nacionais; análise e revisão dos Projetos Pedagógicos dos Cursos como estratégia para apoiar o processo de desenvolvimento de competências discentes. Por fim, na última dimensão, ela sugere que o psicólogo escolar promova discussões acerca do desenvolvimento adulto; desenvolva pesquisas para conhecer o perfil dos estudantes; elabore estratégias para verificar como se dá o desenvolvimento de competências por parte dos estudantes.
É, portanto, com base numa perspectiva crítica, positiva e progressista da educação e de modelos de intervenção mais amplos que se evidencia a possibilidade de a psicologia escolar contribuir para a construção e efetivação de ações, programas e políticas institucionais de responsabilidade social nas Instituições de Educação Superior (IES), em contextos favorecedores do desenvolvimento de identidades solidárias, compatíveis com uma sociedade sustentável.

\section{A responsabilidade social e a Educação Superior}

Historicamente, o termo Responsabilidade Social (RS) foi cunhado para tratar de obrigações de caráter moral das empresas quanto a um comportamento socialmente responsável para, juntamente com os Estados e a sociedade civil, construir um mundo melhor:

Responsabilidade social pode ser definida como o compromisso que uma organização deve ter com a sociedade, expresso por meio de atos e atitudes que a afetem positivamente, de modo amplo, ou a alguma comunidade, de modo específico (...). Assim, numa visão expandida, responsabilidade social é toda e qualquer ação que possa contribuir para a melhoria da qualidade de vida da sociedade (Ashley, 2002, p. 06-07).

O desejo de um mundo melhor, possibilitado pela inclusão social e defendido pelas empresas, já era retórica nas instituições de ensino superior (IES) que, emergidas nesse espírito de época, aprofundaram as discussões sobre a responsabilidade social, haja vista que a escola e, no caso da Educação Superior brasileira, as faculdades, universidades e centros universitários são espaços privilegiados de formação. Elas são responsáveis pelo processo de formação e profissionalização das pessoas por meio da relação crítica e reflexiva com aspectos técnicos, teóricos, éticos e morais implicados na vida em sociedade nos termos da Lei de Diretrizes e Bases da Educação Nacional (1996). Nesse contexto, a ética é compreendida como desejo de uma vida boa compartilhada (Douerk, 2011; Ricoeur, 1990), assente na solidariedade, justiça e responsabilidade (Sousa, 2011).

Ao explicitar que a Educação Superior é responsável por formar profissionais comprometidos com o meio social em que estão inseridos, a LDB (1996) aponta para a responsabilidade social das instituições que a concretizam, uma vez que esse meio social extrapola o contexto da IES e se estende para o conjunto de pessoas, recursos naturais e instrumentais, sejam eles tecnológicos ou não, que compõem o espaço de vida e de ação dessas pessoas. Espaços onde os estudantes e os demais membros da comunidade acadêmica, orientados teórica e metodologicamente, atuam na gestão e prática de projetos com vistas à promoção do outro e da sociedade, mas, também, de si mesmos nesse processo.

Portanto, a responsabilidade social se efetiva na construção da cidadania, na qual, com uma perspectiva 
transdisciplinar de atuação pedagógica e profissional, ocorre a circulação e o entrelaçamento de saberes acadêmicos e populares, em um processo singular de aprendizagem e de produção de conhecimento em torno, inclusive, dos desafios emancipatórios da sociedade local e global. Entende-se emancipação como justiça capacitante e justiça como a distribuição de bens materiais, trabalho, processos de decisão, cultura e reconhecimento (Sousa Santos, 2007).

Além da LDB, a lei relativa ao Sistema de Avaliação da Educação Superior (SINAES), instituída em 2004, regulamenta que as IES brasileiras devem concretizar suas ações educacionais em quatro pilares, acrescentando aos anteriores - ensino, pesquisa, extensão - a responsabilidade social. Nessa perspectiva, a responsabilidade social torna-se item de avaliação, pois, conforme observa Fagundes (2007), o Ministério da Educação deseja saber se as IES estão cumprindo seu papel de promotoras de inclusão social, inclusive a partir da produção e divulgação dos conhecimentos que constroem no ambiente acadêmico.

Responsabilidade social não é uma atividade separada da educação, e sim uma nova forma de educação, mais abrangente e consciente; não se restringe a atividades isoladas em determinadas datas; ao contrário, incorporase ao dia-a-dia das pessoas, intrínseca em cada gesto, em cada pensamento. (Pereira, 2003, p. 232)

Assim, a responsabilidade social nas IES não pode ser executada apenas como um cumprimento de leis, ela precisa ser debatida nos diferentes espaços acadêmicos como uma nova ordem social, uma nova forma de conceber o mundo, as pessoas e as relações que elas estabelecem entre si e o meio ambiente. Então, não cabe falar em RS como um pilar das IES, mas como uma missão inerente à sua natureza: "o sentido essencial da responsabilidade social da Educação Superior consiste em produzir e socializar conhecimento que tenha não só mérito científico, mas também valor social e formativo" (Dias Sobrinho, 2005, p. 28).

A RS é uma forma comprometida de ver e atuar no espaço acadêmico global, ou seja, com a instituição e as pessoas que a compõem, preocupadas umas com as outras e, também, com o mercado de trabalho e com as comunidades que acolhem e compõem a IES. Trata-se, nas palavras de Pereira (2003, p. 235), de

privilegiar a integração comunitária, envolvendo docentes e discentes no estudo da realidade local, visando à busca de soluções técnico-políticas e práticas para as questões de interesse da comunidade; fomentar a educação continuada que fortaleça a consciência crítica, criadora, técnica e ética, gerando novos conhecimentos; apoiar a criação e produção cultural, integrando-se à ação educativa e aos diferentes contextos sociais da região.

Nesse contexto, entendemos que a responsabilidade social universitária se refere a um conjunto de ações, intencionalmente planejadas e coletivamente discutidas, que são empreendidas na universidade, centro universitário ou faculdade que: a) revelam preocupação e práticas favorecedoras do bem estar do outro e de si, seja dentro da instituição ou fora dela; b) propõem mudanças contínuas nas rotinas internas da instituição para melhoria das relações internas e externas; c) institucionalizem a solidariedade como finalidade e meio das ações empreendidas na instituição de ensino; d) intensificam e aprimoram os fluxos de comunicação dentro e fora das IES; e e) evidenciam preocupação e práticas tendentes à sustentabilidade.

Com isso, temos que a construção de IES socialmente responsáveis passa, também, pela integração das equipes de trabalho da própria IES. Nesse sentido, a psicologia escolar se mostra como uma área do conhecimento e da atuação da psicologia potencializadora das ações e da implantação de programas de responsabilidade social universitária por ter em seu corpo teórico e prático um conjunto de saberes e técnicas relacionados à mobilização para a reflexão e ação coletivas.

O objetivo deste artigo é apresentar a sistematização de um Programa de Responsabilidade Social para a Educação Superior a partir de uma experiência de pesquisa-ação realizada por um grupo de três psicólogas com formação em psicologia escolar de uma faculdade privada do Distrito Federal, a partir de agora nomeada FT, com o apoio das variadas equipes de trabalho da instituição, como: secretaria, biblioteca, informática, coordenações de cursos, para citar alguns.

\section{Método}

A FT é uma instituição privada de ensino que tem como missão "educar, em nível superior, para o trabalho em atividades de comércio de bens e serviço, turismo e saúde" (Faculdade de Tecnologia, 2007). Suas atividades iniciaram-se em fevereiro de 2007 com duas unidades de funcionamento e com dois cursos de graduação tecnológica. No seu início, a faculdade contava com 22 técnicos, 13 professores e 90 alunos em cada unidade (FT tinha duas unidades: uma na região central do Distrito Federal e outra na região periférica do distrito). Atualmente, a faculdade conta com 40 técnicos, 67 professores e 1.103 alunos divididos em dois turnos (matutino e noturno), duas unidades, quatro cursos de graduação e três cursos de pós-graduação lato-sensu.

Para a construção do Programa de Responsabilidade Social para a Educação Superior, utilizamos a metodologia da pesquisa-ação, entendendo que, na área educacional, esta tem a tarefa de promover melhoras qualitativas nos diversos processos que acontecem na escola. Os professores e pesquisadores se valem dessa tecnologia metodológica para, a partir de um problema, planejarem, implementarem, descreverem e avaliarem processos pedagógicos mais ou menos amplos (Tripp, 2005).

O desafio da equipe de psicologia escolar era sistematizar um programa de responsabilidade social universitária que desse conta de: a) transformar documentos ins- 


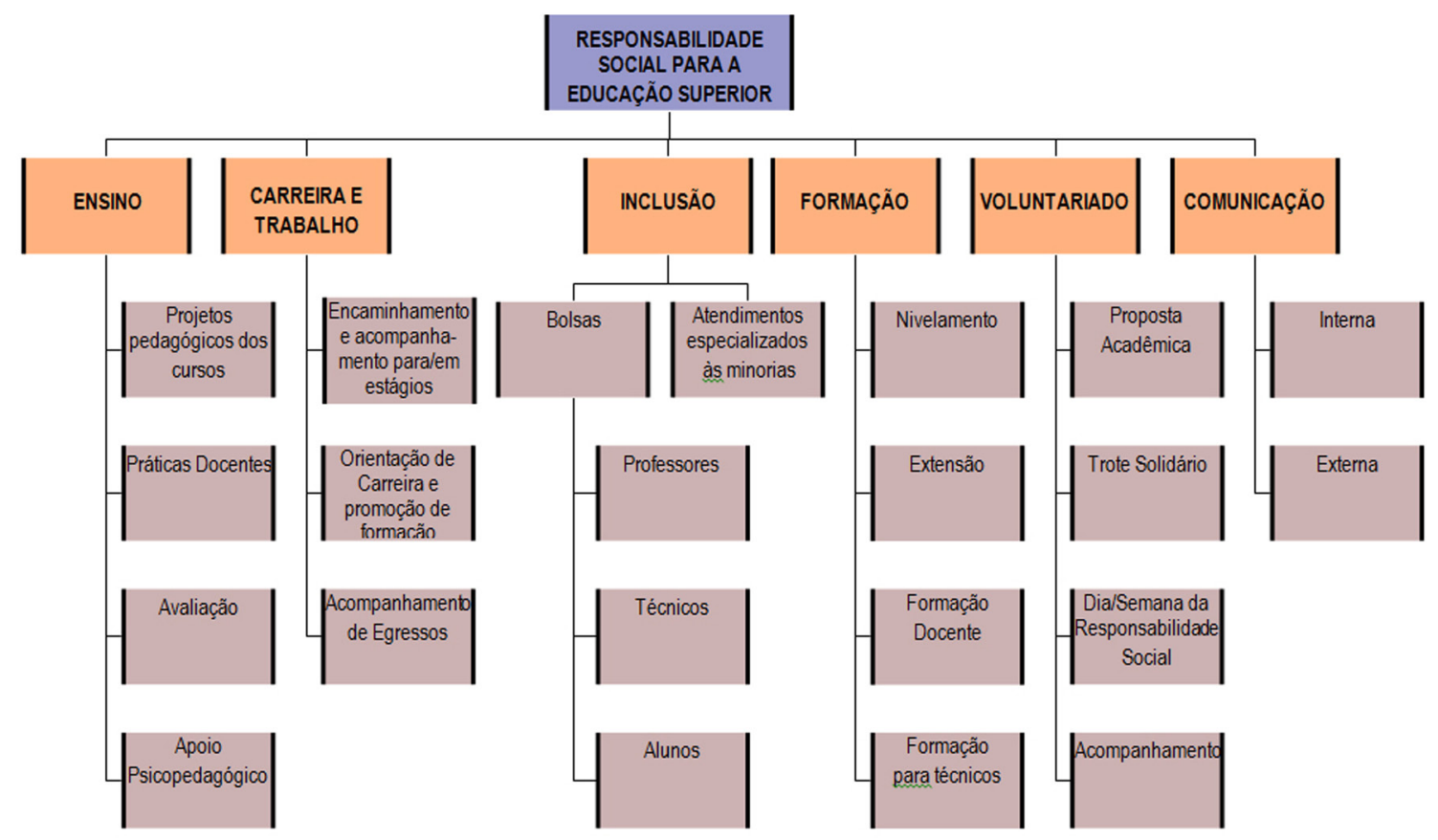

Figura 1. Modelo de Responsabilidade Social para a Educação Superior.

titucionais em práticas sociais e institucionais voltadas para uma educação favorecedora de solidariedade e sustentabilidade, entendendo sustentabilidade como a possibilidade de reduzir desigualdades intrageracionais e, ao mesmo tempo, evitar uma degradação que provoque desigualdades intergeracionais (Bursztyn, 2001); b) transformar práticas de responsabilidade social assistencialistas em práticas mobilizadoras de posicionamentos comprometidos com a promoção social; c) aumentar a interação das equipes de trabalho dentro da IES; d) promover a interação entre as equipes de trabalho e os estudantes da IES; e) aproximar os estudantes das necessidades práticas das comunidades vizinhas à IES para refletir, com elas, alternativas de solução; e f) produzir conhecimento e torná-lo acessível tanto à comunidade interna quanto à comunidade externa à IES.

Para tanto, a equipe promoveu, a partir da metodologia da pesquisa-ação, encontros sistemáticos com todos os segmentos da instituição - docentes, técnicos, discentes e parceiros da FT - para conhecer cada um deles e suas necessidades, ao mesmo tempo em que eram discutidas possibilidades de ações relativas à responsabilidade social da FT. Assim, por exemplo, na medida em que a equipe se reunia com um grupo, já planejava um conjunto de ações que eram executadas e avaliadas com os participantes.

Esse processo de ação-reflexão-ação, isto é, essa práxis mediada pelos conhecimentos teóricos e práticos da psicologia escolar e do desenvolvimento, permitiu a sistematização de um programa de responsabilidade social não só para FT, mas para as IES em geral, uma vez que está pautada na atuação institucional da psicologia escolar (Gu- zzo, 2001; Marinho-Araújo, 2009; Martínez, 2010; Oliveira \& Marinho-Araújo, 2009; Oliveira, 2011).

\section{Resultados: um Programa de Responsabilidade Social para a Educação Superior}

O programa apresentado a seguir é multidimensional, na medida em que permeia o cotidiano da IES desde suas políticas e práticas organizacionais até sua interação com a comunidade local e global. Assim, o programa apresenta seis grandes dimensões institucionais a partir das quais projetos específicos podem ser desenvolvidos com o intuito de proporcionar contextos de formação cidadã aos e com estudantes de graduação, de pós-graduação e de extensão, professores, técnicos-administrativos e comunidades locais e globais.

Destacamos que essa proposta de atuação tem por pressuposto que a "educação para a cidadania não pode ser concebida apenas como um conteúdo programático, já que implica uma tomada de consciência da complexidade de elementos científicos, culturais, políticos, econômicos e sociais envolvidos no labor formativo" (Pereira, 2003, p. 123).

A Figura 1 apresenta o esquema do Programa de Responsabilidade Social desenvolvido a partir da experiência de pesquisa-ação na FT.

A seguir, cada grande dimensão construída é definida e exemplificada pelas ações que foram desenvolvidas na FT. Cada uma delas apresenta aspectos com os quais a IES precisa se preocupar para a formação solidária e humana 
das pessoas que vivem e convivem nela e fora dela. Por formação solidária e humana entendemos a capacidade de "reciprocidades através da construção e do reconhecimento da intersubjetividade" (Sousa Santos, 2007, p. 81).

Dimensão 1 - Políticas de Ensino: diz respeito às ações da IES para a promoção da RS no âmbito do ensino.

a) Projetos Pedagógicos dos Cursos (PPC): refere-se à preocupação da IES de que seus cursos de graduação e pós-graduação contemplem a discussão de temas como ética, responsabilidade social, moral, sustentabilidade e solidariedade, seja em disciplinas específicas ou como tema transversal. Na FT, os PPCs foram elaborados pelos professores e coordenadores da instituição, com assessoria da equipe de psicologia escolar, de forma a garantir: a discussão de RS nos cursos e a associação entre os conhecimentos específicos da área e a prática profissional, essencial para os cursos tecnológicos brasileiros de nível superior.

b) Prática docente: diz respeito às ações dos professores para a promoção do ensino integrado e contextualizado. $\mathrm{Na} \mathrm{FT}$, os cursos de formação docente continuada permitem o estudo e a discussão de propostas de intervenção pedagógica que contemplem a integração entre as disciplinas.

c) Avaliação: diz respeito às práticas de avaliação da aprendizagem e à avaliação institucional. Quanto às avaliações de aprendizagem, a FT adotou, desde 2009, a avaliação integrada, construída a partir da articulação dos conteúdos e competências explorados nas diferentes disciplinas. Para tanto, o grupo de professores e gestores da FT participou de um curso de 40 horas sobre Plano Político Pedagógico da FT, Plano de Curso e Avaliação. O curso contemplou oficinas e debates que procuravam fomentar a reflexão e a mobilização de recursos para a ação que permitissem práticas docentes integradas, que viabilizassem uma avaliação formal de aprendizagem integrada. Para a capacitação continuada, FT mantém um encontro por mês com os professores e gestores. Além das avaliações integradas realizadas por meio impresso, os docentes foram estimulados a variarem suas avaliações por meio de jogos, feiras, campanhas de marketing, entre outras ações que privilegiavam a mobilização de recursos cognitivos, sociais e emocionais dos estudantes na resolução de desafios práticos.

No que se referia à avaliação institucional, a psicologia escolar se envolveu na coordenação do processo de autoavaliação da FT, especialmente a psicóloga do NAPSI, assessorando a comissão na: delimitação das metas e dos procedimentos, integração dos membros que compõem a Comissão Própria de Avaliação, definição coletiva de responsabilidades, capacitação dessa equipe quanto ao aprofundamento de questões teórico-metodológicas e éticas envolvidas no desenvolvimento da autoavaliação.

d) Apoio psicopedagógico: sob essa designação, estão contempladas ações desenvolvidas com os diferentes segmentos da IES para a promoção do seu desenvolvimento. $\mathrm{Na} F T$, a equipe da psicologia escolar realizou encontros sistemáticos e coletivos com os estudantes para o desenvolvimento pessoal e profissional. Com o corpo do- cente, as ações concentram-se no apoio ao planejamento e realização de atividades em sala de aula, orientação acerca das adequações curriculares necessárias aos alunos com deficiência, discussões de estratégias didático-pedagógicas alternativas e potencializadoras do desenvolvimento de competências discentes. Com o corpo técnico-administrativo, transcorrem encontros voltados ao autoconhecimento, expressão corporal e promoção das relações inter-pessoais e do desenvolvimento profissional. Os encontros tanto com o corpo técnico-administrativo quanto com o corpo docente eram pautados pelas necessidades de cada grupo e, também, pelas necessidades observadas pela equipe.

Dimensão 2 - Programa de Acompanhamento para o trabalho e Relacionamento com o mercado: diz respeito às ações da IES para a formação para o trabalho de uma forma mais ampla, considerando tanto o mercado de trabalho quanto os alunos.

a) Encaminhamento e acompanhamento para/em estágios obrigatórios e não obrigatórios: diz respeito às ações para o ingresso dos alunos em postos de trabalho que permitam a vivência profissional na área de formação e, também, ao acompanhamento dessas atividades por meio da tutoria de um(a) professor(a) da área. No caso da FT, foi criado o programa Fac Talentos, que tinha o objetivo de encaminhar e acompanhar os alunos em atividades de estágio na sua área de formação acadêmica.

b) Orientação de carreira e promoção de formação: diz respeito às ações que a IES promove para orientar os alunos sobre suas carreiras, os caminhos acadêmicos e profissionais que podem seguir; estabelecer o tutoreamento de alunos por alunos mais experientes e/ou professores e, também, para levantar as necessidades de formação específica ou complementação da formação profissional por meio de cursos de extensão e/ou nivelamento. A Fac Talentos tinha e tem a responsabilidade de operacionalizar o programa de coaching e mentoring, no qual os alunos têm espaços formais de escuta e de orientação.

Dimensão 3 - Políticas de Inclusão: diz respeito às estratégias construídas pela IES nos seus documentos institucionais e nas suas rotinas para garantir o acesso à educação, à informação e à construção de conhecimento coletiva e individual.

a) Bolsas: diz respeito à política da IES para a concessão de bolsas de estudos para alunos de graduação, pós-graduação, extensão e, também, para professores e técnicos-administrativos. Na FT, as bolsas de estudo foram determinadas por portarias internas, com a anuência e aprovação da instituição mantenedora. Para professores e técnicos-administrativos, as bolsas também eram regidas pela mantenedora, que concedia bolsas integrais ou parciais para cursos de graduação, pós-graduação e aperfeiçoamento profissional.

b) Atendimentos especializados às minorias: diz respeito às ações da IES para inclusão de pessoas das camadas populares, com deficiência, desempregados, índios, 
negros, mulheres, estrangeiros, entre outras categorias sociais. $\mathrm{Na}$ FT, as maiores ações se referiam ao atendimento às pessoas com deficiência e desempregados. No âmbito do apoio psicopedagógico, desenvolveu-se, sob coordenação do NAPSI, estratégias de adaptação e melhor atendimento aos alunos com deficiência, e a Fac Talentos trabalhou com os alunos desempregados, no sentido de recolocá-los no espaço produtivo.

Dimensão 4 - Políticas de Formação: diz respeito aos documentos e rotinas que a IES dispõe para a formação continuada de alunos, técnicos e professores.

a) Cursos de nivelamento: são cursos da formação básica, voltados principalmente para alunos de graduação, que têm o objetivo de resgatar e construir aprendizagens e hábitos de estudos necessários à formação superior. Na FT, os cursos de nivelamento costumavam ser: português, informática, matemática e inglês básicos, técnica de estudos, entre outros.

b) Cursos de extensão: dizem respeito à oferta de cursos complementares à formação profissional de alunos, professores, técnicos e comunidade. $\mathrm{Na} \mathrm{FT}$, os cursos de extensão ofertados seguiam a missão da faculdade e as necessidades da comunidade acadêmica e da comunidade em geral, inclusive de empresas que procuram cursos in company, isto é, específicos às necessidades da empresa.

c) Formação docente: diz respeito aos programas institucionais direcionados para a capacitação de seus colaboradores, como forma de reformular as práticas docentes e integrar as novas tecnologias e metodologias de ensino que ampliam o poder de ação do professor. Na FT, acontecia especialmente nas Semanas Pedagógicas realizadas no início de cada semestre e contemplava formações teóricas e práticas sobre temas contemporâneos, como: o ensino interdisciplinar, o desenvolvimento por competências e a avaliação da aprendizagem.

d) Formação para técnicos: diz respeito à política da IES para a formação continuada do corpo técnico-administrativo. Na FT, duas vezes por ano, todos os técnicos participavam de cursos de formação relacionados à atuação geral da equipe. Ao longo do ano, a faculdade oferecia bolsas para que os técnicos participassem de cursos ou eventos de interesse específico, relacionados à função de cada um. Quinzenalmente, a equipe de psicologia escolar realizava encontros com o corpo técnico nos quais debatiam temas livres ou direcionados, a partir do desejo do próprio grupo.

Dimensão 5 - Políticas de Voluntariado: diz respeito às ações da IES para a integração entre os diferentes protagonistas da instituição e destes com comunidades locais, bem como de ações de intervenção nessas comunidades, a partir da prática do voluntariado

a) Proposta acadêmica: diz respeito aos objetivos pedagógicos da política de voluntariado, que deve se firmar na certeza de que as práticas de voluntariado geram posicionamentos solidários a partir do momento em que a pessoa ressignifica a si-mesmo/a e o outro na relação de reciprocidade (Sousa, 2011).

b) Trote solidário: diz respeito ao conjunto de ações da IES para recepção dos novos alunos e integração deles à comunidade acadêmica. Na FT, foi construído o trote solidário, que acontecia uma vez por ano e tinha o objetivo de integrar alunos novatos e veteranos, técnicos, professores e comunidade numa ação comunitária que buscava resolver algum problema social emergente numa comunidade local. O trote solidário foi organizado como uma gincana em que os estudantes eram mobilizados a participar de cursos de formação acadêmica e profissional para terem melhores condições de resolver os problemas da comunidade escoIhida. Para tanto, havia uma mobilização externa, ou seja, estudantes e gestores da FT realizavam contatos com instituições das mais diversas naturezas para concretizar a ação comunitária. Esse contato se dava principalmente por meio de visitas sistemáticas à comunidade atendida pelo trote solidário e a empresas e instituições que pudessem contribuir para a execução dos objetivos da gincana que mobilizava o trote, mas também por contatos telefônicos e e-mails.

c) Dia/Semana da Responsabilidade Social: refere-se a um período acadêmico específico, registrado no calendário acadêmico, de ações comunitárias, em que a IES vai "para a rua" construir e divulgar conhecimentos com a comunidade local, além de prestar serviços comunitários e promover ações culturais. No caso das IES privadas, geralmente há o estabelecimento de um dia, que é marcado pela Associação Brasileira das Mantenedoras do Ensino Superior - ABMES (2007). No caso das IES públicas, há uma variabilidade grande de atuação. Cada Conselho Superior determina como será esse dia ou semana, que pode ser chamado de Semana de Extensão ou Semana Acadêmica ou Semana Universitária. Assim, independente do nome e tempo de duração, o que marca essa subdimensão é a mobilização da IES para a prática da solidariedade dentro e fora da instituição. Na FT, esse dia era a finalização da gincana, quando os objetivos alcançados durante o período de mobilização da gincana eram apresentados/doados para a comunidade atendida. Por exemplo, em 2009, foram entregues materiais para a reforma de uma escola pública do Distrito Federal, arrecadados pelos grupos participantes do Trote Solidário daquele ano. Esse era um dia de imersão na comunidade atendida, com programação que contempla atividades culturais, atendimentos médico-hospitalares e cursos de rápida formação profissional, em que toda a comunidade acadêmica e parceiros eram convidados a participar voluntariamente das ações do dia.

d) Acompanhamento: diz respeito às ações da IES para acompanhar as consequências de suas ações solidárias com a comunidade. Esse acompanhamento deve atentar tanto para os ganhos dos voluntários como os ganhos da comunidade, garantindo, sempre que possível, continuidade das ações planejadas na parceria IES-Comunidades. Na FT, o acompanhamento era feito por meio de reuniões sistemáticas com a comunidade atendida que gerou o trote solidário. 
Dimensão 6 - Políticas de Comunicação: diz respeito aos regulamentos e às práticas relacionadas à divulgação de informações à comunidade acadêmica e à comunidade em geral. Relaciona-se ao fluxo de informações tanto dentro quanto fora da IES.

a) Comunicação interna: diz respeito às políticas e ações da IES para estabelecer e construir fluxo de informações internas, como estratégia fundamental para o fortalecimento da identidade, incluindo a cultura organizacional da IES. Na FT, para que o fluxo de informação acontecesse de forma rápida e eficiente, foram adotados como recursos para a comunicação interna: portarias institucionais, boletim informativo, e-mails, SMS, murais e blogs. Além dessas ações, a FT mantinha um programa de comunicação interna chamado Escuta Legal, em que os alunos, professores, técnicos e professores eram "ouvidos" por meio do e-mail institucional Fale Conosco, das caixas de sugestões e dos Café com a Direção, ocasião em que a comunidade interna era recebida pelos gestores e pela psicóloga do NAPSI para debater temas relacionados aos seus interesses.

b) Comunicação externa: diz respeito às políticas e ações da IES para estabelecer e manter fluxo de informações com a comunidade e tem o fundamental objetivo de aproximar a IES e suas ações da comunidade em geral, divulgando e difundindo os conhecimentos construídos pelos diversos personagens que a compõem. Na FT, a comunicação externa envolvia meios de comunicação convencionais, como site na internet, televisão e publicações em jornais impressos; meios recentes, como o Twitter; cafés com empresários, com o objetivo de conhecer as necessidades do mercado nas áreas de cursos da faculdade, bem como apresentar os estudantes e cursos para os empresários convidados; e, por fim, comunicação científica, realizada pela publicação semestral de uma revista científica, que tem o objetivo de divulgar conhecimentos construídos por pesquisadores brasileiros e internacionais sobre educação profissional.

\section{Discussão e Conclusões}

O Programa de Responsabilidade Social para Educação Superior apresentado neste artigo demonstra avanços a partir da atuação direta da psicologia escolar na gestão institucional e o seu comprometimento com a promoção da solidariedade e sustentabilidade como filosofias pedagógicas, especialmente no que diz respeito à formação integral do estudante e à formação continuada de professores e técnicos.

Para além do que Witter (1999) e Martínez (2010) apontam como atuação da psicologia escolar na/para a Educação Superior, concordamos com Marinho-Araújo (2009) sobre as três dimensões destacadas para a atuação do psicólogo escolar nas IES: (a) Gestão de Políticas, Programas e Processos Educacionais, (b) Propostas Pedagógicas e funcionamento de cursos e (c) Perfil do estudante. Acrescentamos a essas possibilidades de atuação uma quarta que se refere ao apoio a atuações de responsabilidade social universitária, oportunizando o compartilhamento, construção e difusão de conhecimento em contextos potencialmente favoráveis ao desenvolvimento de identidades solidárias e à construção de uma sociedade sustentável.

Nesse sentido, o psicólogo escolar, na Educação Superior, precisa atuar no fomento de políticas e programas de aprendizagem e de atuação profissional que possibilitem posicionamentos pessoais e profissionais assentes na solidariedade, na justiça e na responsabilidade, elementos de base da sustentabilidade.

O programa que apresentamos neste trabalho evidencia novas possibilidades de atuação dos profissionais de psicologia escolar na Educação Superior com vistas à formação de pessoas, profissionais e instituições preocupadas com as dinâmicas internas e com os processos mútuos de desenvolvimento e aprendizagem. Estabelecendo a responsabilidade social como diretriz de trabalho, propondo programas teoricamente fundamentados e metodologicamente traçados com vistas à emancipação pessoal e coletiva das pessoas que compõem a comunidade universitária, interna e externamente, a psicologia escolar concretiza sua função social, ampliando sua atuação para uma forte integração com a comunidade local e global.

Enfim, este estudo enfoca as atuações de responsabilidade social universitária como oportunidade de compartilhamento, construção e difusão de conhecimento em contextos potencialmente favoráveis ao desenvolvimento de identidades solidárias. E aponta modos como a psicologia escolar pode contribuir nos processos cotidianos para a realização dessas ações assumidas pelas IES em um esforço teórico e metodológico de integrar ensino, pesquisa e extensão com vistas ao desenvolvimento humano em sua dimensão ética e à construção de uma sociedade tendente à sustentabilidade.

\section{Referências}

Ashley, P. A. (Coord.) (2004). Ética e responsabilidade social nos negócios. São Paulo: Saraiva.

Associação Brasileira de Mantenedoras de Ensino Superior. (2007). Responsabilidade Social. Ensino Responsável 2006. Relatório das atividades sociais realizadas pelas IES, ano $2, n^{\circ} 2$.

Bursztyn, M. (2001). Políticas públicas para o desenvolvimento (sustentável). Em M. Bursztyn (Org.), A difícil sustentabilidade: política energética e conflitos ambientais (pp. 59-76). Rio de Janeiro: Garamound.

Douerk, S. S. (2011). Paul Ricoeur e Emmanuel Lévinas: um elegante desacordo. São Paulo: Ed. Loyola.

Dias Sobrinho, J. (2005). Educação Superior, globalização e democratização. Qual universidade? Revista Brasileira de Educação, 28, 164-173. 
Faculdade de Tecnologia. (2007). Plano de Desenvolvimento Institucional. Brasília: FT.

Fagundes, G. M. (2007). A responsabilidade social das Instituições de Educação Superior sob o prisma dos direitos sociais previstos na Constituição Federal de 1988. Instituto Latino-Americano de Planejamento Educacional, Texto não publicado, Brasília, DF.

Guzzo, R. L. S (2001). Saúde psicológica, sucesso escolar e eficácia da escola: desafios do novo milênio para a Psicologia escolar. Em Z. A. P. Del Prette (Org.), Psicologia escolar e Educacional: saúde e qualidade de vida (pp. 25-42). Campinas, SP: Editora Alínea.

Lei n. 9.394, de 20 de dezembro de 1996. (1996, 23 de dezembro). Estabelece as Diretrizes e Bases da Educação Nacional. Diário Oficial da União, seção 1. Brasília, DF.

Lei n. 10.861, de 14 de abril de 2004. (2004). Institui o Sistema Nacional de Avaliação da Educação Superior - SINAES. Brasília: MEC.

Marinho-Araújo, C. M. (2009). Psicologia escolar na Educação Superior: novos cenários de intervenção e pesquisa. Em C. M. Marinho-Araújo (Org.), Psicologia escolar: novos cenários e contextos de pesquisa, formação e prática (pp. 155-202). Campinas, SP: Alínea.

Martínez, A. M. (2010). O que pode fazer o psicólogo na escola? Em Aberto, 23(83), 39-56.

Oliveira, C. B. E. (2011). A atuação da Psicologia Escolar na Educação Superior: proposta para os Serviços de Psicologia. Tese de Doutorado, Universidade de Brasília, Brasília, DF>
Oliveira, C. B. E \& Marinho-Araújo, C. M (2009). Psicologia escolar: cenários atuais. Estudos e Pesquisas em Psicologia, 9(3), 648663.

Pereira, R. da S. (2003). Responsabilidade Social na Universidade. Revista Gerenciais, 2, 113-125

Ricoeur, P. (1990). Soi-memê comme um autre. Paris: Seuil.

Sousa, M. do A. (2011). Desenvolvimento humano no contexto do voluntariado: interfaces com a ética e a sustentabilidade. Tese de Doutorado, Instituto de Psicologia, Universidade de Brasília, Brasília, DF.

Sousa Santos, B. A crítica da razão indolente, contra o desperdício da experiência. São Paulo: Cortez, 2007.

Tripp, D. (2005). Pesquisa-ação: uma introdução metodológica. Educação e Pesquisa, 31(3), 443-466.

Vinha, T.P. (2003). Os conflitos interpessoais na relação educativa. Tese de Doutorado, Universidade Estadual de Campinas, Campinas, São Paulo.

Witter, G. P. (1999). Psicólogo escolar no ensino superior e a Lei de Diretrizes e Bases. Em R. S. L. Guzzo (Org.), Psicologia escolar: LDB e educação hoje (pp. 83-104). Campinas, SP: Editora Alínea.

Recebido em: 06/02/2012

Reformulado em: 23/07/2012

Aprovado em: 27/07/2012

\section{Sobre as autoras}

Juliana Eugênia Caixeta (eugenia45@hotmail.com)

Faculdade UnB Planaltina, Doutorado.

Endereço Postal: QI 3 Bloco P apto. 305 - Guará I, Brasília-DF. CEP: 71020162.

Maria do Amparo de Sousa (ampmsousa@gmail.com)

Universidade Católica de Brasília, Doutorado.

Endereço Postal: SRES Q. 4 Bloco E casa 8 - Cruzeiro, Brasília-DF. CEP: 70648053.

Este trabalho contou com a colaboração da Professora Doutora Cynthia Bisinoto Evangelista de Oliveira, da Faculdade UnB Planaltina, e derivou de um trabalho apresentado no Primeiro Seminário Internacional Contributos da Psicologia em Contextos Escolares, 2010.

A segunda autora recebeu auxílio financeiro da CAPES/DGU - Cooperação Internacional Brasil/Espanha, processo n 23038.004801/2008-88. 